\title{
(a) OPEN ACCESS \\ Challenging the view that lack of fibre causes childhood constipation
}

\author{
David Tappin, ${ }^{1}$ Mariusz Grzeda, ${ }^{2}$ Carol Joinson, ${ }^{2,3}$ Jon Heron ${ }^{2}$
}

- Additional material is published online only. To view please visit the journal online (http://dx.doi.org/10.1136/ archdischild-2019-318082)

${ }^{1}$ Scottish Cot Death Trust, University of Glasgow, Glasgow, UK

${ }^{2}$ Population Health Sciences, University of Bristol, Bristol, UK ${ }^{3}$ Centre for Child and

Adolescent Health, University of Bristol, Bristol, UK

\section{Correspondence to}

Professor David Tappin, Scottish Cot Death Trust, University of Glasgow, Glasgow G3 8S, UK; david.tappin@glasgow.ac.uk

Received 14 August 2019 Revised 12 February 2020 Accepted 17 February 2020

Published Online First

10 March 2020
ABSTRACT

Objectives To assess evidence supporting the view that 'low fibre causes childhood constipation'.

Design Triangulation integrated three approaches: a systematic review NICE guideline CG99 examining effectiveness of increasing fibre; a cohort study, Avon Longitudinal Study of Parents and Children (ALSPAC), to assess if constipation (or hard stools) can precede fibre intake at weaning; and a literature search for twin studies to calculate heredity.

Setting CG99 examined the literature regarding the effectiveness of increasing fibre. ALSPAC asked parents about: hard stools at 4 weeks, 6 months and 2.5 years and constipation at age 4-10 years, as well as fibre intake at 2 years. Twin studies and data from ALSPAC were pooled to calculate concordance of constipation comparing monozygotic and dizygous twin pairs.

Participants CG99 reported six randomised controlled trials (RCTs). ALSPAC hard stool data from 6796 children at 4 weeks, 9828 at 6 months and 9452 at 2.5 years plus constipation data on 8401 at 4-10 years were compared with fibre intake at 2 years. Twin studies had 338 and 93 twin pairs and ALSPAC added a further 45

Results Increasing fibre did not effectively treat constipation. Hard stools at 4 weeks predated fibre and at 6 months predicted lower fibre intake at 2 years $(p=0.003)$. Heredity explained $59 \%$ of constipation.

Conclusions RCTs indicate that increasing fibre is not an effective treatment for constipation in children. Hard stools can precede and predict later fibre intake. Genetic inheritance explains most childhood constipation. Extended treatment with stool softeners may improve fibre intake and limit long-term damaging sequelae of constipation.

\section{INTRODUCTION}

Constipation affects $10 \%$ of children. ${ }^{1}$ It can be severely disabling resulting in medical and surgical intervention and poor quality of life including mental health, ${ }^{2}$ particularly if associated with soiling. Lay belief is that low fibre or lack of fluids causes constipation, ${ }^{3}$ a view held by many health professionals, ${ }^{4}$ leading to delayed laxative treatment. ${ }^{4}$ Parents are reluctant to administer longterm laxatives because of a second false lay belief: 'long term use of laxatives makes the bowel lazy'. Parents feel guilty ${ }^{56}$ exacerbated by dietary advice perceived as 'you are not feeding your child properly'. Effective laxative treatment can be delayed for months or years turning a treatable condition into a chronic intractable problem.

In 2010, $\mathrm{NICE}^{4}$ recommended against dietary interventions alone as first-line treatment for

\section{What is already known on this topic?}

It has been observed for children that identical twins have a much higher concordance for constipation compared with non-identical twins.

- It is known that diet, particularly a low fibre diet, is associated with constipation.

\section{What this study adds?}

- This study suggests that constipation in children is not caused by low dietary fibre but by a genetic predisposition to hard stools and subsequent constipation.

- Extended effective medical treatment of hard stools in infancy and childhood may increase subsequent fibre intake and reduce the prevalence of long-term idiopathic constipation.

- This study provides a biological explanation for NICE guideline CG99 evidence-based guideline statement 'Do not use dietary interventions alone as first-line treatment for idiopathic constipation'.

idiopathic constipation in children. However, beliefs about fibre persist, perhaps because an alternative cause of constipation in children has not been found. This paper uses triangulation ${ }^{7}$ to examine the question 'does low fibre cause constipation in children', utilising data collected with different methodologies, together to try to ascertain causality. The evidence from each context or methodology alone is not adequate to prove or refute a cause. However, if methodologies in different contexts point in the same direction, then causation can be examined more credibly.

\section{METHODS}

Dataset 1: NICE guideline CG99 with 2017 review update

NICE used standard search and assessment to review evidence that increasing dietary fibre was an effective treatment for childhood constipation. ${ }^{4}$ Within the guideline scope, 'Management' included: 'dietary manipulation, fruits, vegetables (fibres and roughage), fruit juices, cereals'. The question was: 'What is the clinical effectiveness of dietary modification for ongoing treatment or maintenance in children with chronic idiopathic constipation?' Studies included six randomised controlled trials (RCTs). ${ }^{8-13}$ 


\section{Dataset 2: data from a UK birth cohort}

The sample comprised participants from the Avon Longitudinal Study of Parents and Children (ALSPAC). Detailed information available at (http://www.bristol.ac.uk/alspac) includes a fully searchable data-dictionary (http://www.bris.ac.uk/alspac/ researchers/data-access/data-dictionary). Pregnant women resident in the former Avon Health Authority in South West England, having an estimated date of delivery between 1 April 1991 and 31 December 1992, were approached, resulting in a cohort of 14541 pregnancies. ${ }^{14}$ Of 13978 singletons/twins alive at 1 year, 24 participants withdrew consent leaving 13954 participants.

\section{Fibre intake at age 2 years}

A food frequency questionnaire ${ }^{15} 16$ was administered to the main carer when their child was 2 years old. Responses to foods containing fibre were selected ${ }^{17}$ : baby rice, baby cereal, breakfast cereal, savoury vegetable, potatoes, other vegetables, baked beans, green peas, other legumes, figs, raw apple, other raw fruit, raw carrot, other raw vegetables and nuts/nut products. Frequency of consumption was recorded in a continuous format (eg, times/week) yielding data with a wide range of values and notable digit preference. These data were collapsed to form a set of ordinal variables (never or $<1 /$ week; $1-3$ times/week; 4-7 times/week; $>7$ times/week). Polychoric principal component analysis was performed, and the first component, describing $30.4 \%$ of total item variance, was chosen as the continuous standardised measure of fibre consumption (online supplementary tables S1 \& S2). Online supplementary figure S1 groups the fibre measure into five quintiles showing the average frequency of intake for each food type within each quintile.

\section{Hard stools and constipation}

At 4 weeks, 6 months and 2.5 years, questionnaires were administered about stool consistency ${ }^{18}$ asking about frequency of hard stools with response options at 4 weeks: 'Always', 'Sometimes',
'Occasionally' and 'Never' and at 6 months and 2.5 years: 'Usually', 'Sometimes' and 'Never'.

At ages $4 \frac{1}{2}, 5 \frac{1}{2}, 6 \frac{1}{2}, 71 \frac{1}{2}$ and $91 \frac{1}{2}$ years, parents were asked about their child's constipation in the past 12 months with options: 'Yes, and saw a doctor'; 'Yes, did not see the doctor' and 'No, did not have'. Responses were dichotomised to indicate presence of any constipation at each age. These data have been analysed previously using longitudinal latent class analysis to separate patterns of constipation. In addition to a normative class (82\%; very low probability of constipation), we found evidence for three separate classes who experienced some degree of constipation: early occurrence $(7 \%$ of children suffered constipation until 6 years), late occurrence ( $8 \%$ had constipation emerging after 6 years) and persistent (3\% had a high probability throughout). We found a strong association between hard stools at 2.5 years and constipation during later childhood. ${ }^{19}$

\section{Confounders}

Potential confounders including child's sex and socioeconomic variables measured ${ }^{20}$ were considered (see table 1 footnote for details). For analyses investigating prospective associations between diet and hard stools, the duration of any breast feeding and age of introducing cow's milk and solid food, were included. Online supplementary table S3 shows many of the socioeconomic variables and their strong association with fibre intake. This contrasts with lack of association between constipation and socioeconomic variables using this cohort. ${ }^{19}$

\section{Statistical modelling}

For models with ordinal/nominal outcome variables (eg, stool consistency), multinomial regression models were used. For models of fibre intake, OLS regression was applied. For each model, unadjusted estimates were derived followed by adjustments for confounders.

Table 1 Prospective association between frequency of hard stools at (1) 4 weeks and (2) 6 months and fibre intake at 2 years

\begin{tabular}{|c|c|c|c|}
\hline & Unadjusted & Adjusted 1 & Adjusted 2 \\
\hline & Beta $(95 \% \mathrm{Cl})$ & Beta $(95 \% \mathrm{CI})$ & Beta $(95 \% \mathrm{Cl})$ \\
\hline \multicolumn{4}{|c|}{ (1) Frequency of hard stools at age 4 weeks } \\
\hline Never & 0.00 ref & 0.00 ref & 0.00 ref \\
\hline Sometimes/occasionally & $-0.215(-0.268$ to -0.162$)$ & -0.051 ( -0.109 to 0.008$)$ & $0.038(-0.033$ to 0.109$)$ \\
\hline Always & $-0.479(-0.677$ to -0.281$)$ & $-0.229(-0.445$ to -0.013$)$ & $-0.111(-0.331$ to 0.109$)$ \\
\hline Omnibus $p$ value & $P<0.001$ & $P=0.034$ & $P=0.293$ \\
\hline $\mathrm{R}^{2}$ & 0.012 & 0.0445 & 0.0488 \\
\hline $\mathrm{N}$ & 6796 & 5249 & 5126 \\
\hline \multicolumn{4}{|c|}{ (2) Frequency of hard stools at age 6 months } \\
\hline Never & 0.00 ref & 0.00 ref & 0.00 ref \\
\hline Sometimes & $-0.114(-0.158$ to -0.070$)$ & $-0.089(-0.135$ to -0.043$)$ & $-0.077(-0.124$ to -0.029$)$ \\
\hline Usually & $-0.171(-0.237$ to -0.104$)$ & $-0.103(-0.172$ to -0.034$)$ & $-0.092(-0.163$ to -0.021$)$ \\
\hline Omnibus $p$ value & $\mathrm{P}<0.001$ & $\mathrm{P}<0.001$ & $P=0.003$ \\
\hline$R^{2}$ & 0.0036 & 0.0511 & 0.0558 \\
\hline $\mathrm{N}$ & 9828 & 7550 & 7214 \\
\hline
\end{tabular}

Estimates represent standardised differences in continuous measure of fibre intake relative to the group who are reported to never suffer from hard stools.

Adjusted 1: adjusted for sex, and sociodemographic variables (mother's social class, based on the occupational social class classification dichotomised into non-manual (professional, managerial and skilled occupations) and manual (comprising partly skilled or unskilled professions); early parenthood indicating if the mother was under 19 years when giving birth to the study child; level of maternal education: <0-level (ie, no school leaving qualification), 0 -level (school leaving qualifications obtained at age 16 years) and A-level/degree (qualifications from further education); housing tenure: mortgaged/owned; privately rented; subsidised rented; and experience of material hardship (dichotomous variable); household income equivalised, a composite measure of disposable income split into quintiles.).

Adjusted 2: (1) further adjusted for breast/bottle feeding status in first 4 weeks/(2) further adjusted for breastfeeding duration in first 6 months and timing of introduction of both milk and solids. 


\section{Dataset 3: twin data}

Limited published data exist regarding twin zygosity and concordance of constipation in children. (1) a well-regarded Paediatric Gastroenterology Textbook ${ }^{21}$ referenced one study published in 1971 describing twin concordance for constipation aged 6-19 years. ${ }^{22}$ Raw data were extracted for twin zygosity and concordance of constipation. (2) Further searching of the literature used 'child', 'constipation' and 'twin' as keywords and 'title' words to examine whether additional useful published data were available. Ovid Medline, Embase and Web of Science databases were searched from 1946 to 2019. One additional Japanese twin study $^{23}$ was found with parent-reported constipation age 3 years. Data were extracted. 'Hereditary' was substituted for 'twin' but did not provide literature with further extractable data. (3) Data on twins among ALSPAC participants was included.

All three studies had zygosity derived in accepted but different ways. For the 1971 US twin study, ${ }^{22}$ 'Zygosity was determined clinically and, by matching blood groups. The blood groups used were ABO, Rh (CcDEe), MNSs, P, Fya, K, and Jka. Blood matching was omitted only when dizygosity was clinically selfevident'. ${ }^{24}$ For the Japanese twin study, ${ }^{23}$ fingerprints were used, and for those where zygosity could not be determined, blood typing was employed using 20 genetic markers. Finally, for ALSPAC, zygosity was defined using DNA tests, ${ }^{14}$ and further twins were determined as dizygous if of different sex.

\section{Statistical modelling}

Heredity was derived using a standard approach that gives values from $0 \%$ to $100 \%$ corresponding to fully heritable (solely due to genetics). For example, adult height is strongly heritable $80 \%$. Heritability was calculated as the difference in variance (ie, 1 - concordance rate) between dizygotic and monozygotic twins divided by the variance in dizygotic twins. ${ }^{25}$

\section{RESULTS}

\section{Dataset 1: NICE guideline CG99}

The NICE guideline report found no evidence to suggest increasing fibre-rich foods was effective to treat or manage constipation and that adding fibre to an already healthy diet could be detrimental, exacerbating symptoms and increasing soiling. The Guideline Development Group recommended 'children should be advised to eat a healthy diet, including fibre containing foods as outlined by the Paediatric Group of the British Dietetic Association in "Food for the Growing Years" and "Food for the School Years". ${ }^{26}$ The guideline did however suggest to achieve: 'Adequate fibre: Recommend including foods with a high fibre content (such as fruit, vegetables, high-fibre bread, baked beans and wholegrain breakfast cereals)'. ${ }^{4}$ There was insufficient evidence to recommend fibre supplements in treatment or management of idiopathic constipation. ${ }^{4}$ The 2017 guideline update stated: 'New evidence is unlikely to change guideline recommendations'.

\section{Dataset 2: data from a UK birth cohort}

One per cent of babies always had hard stools age 4 weeks, $12 \%$ usually age 6 months and 28\% usually at 2.5 years. table 1 shows the association between hard stool frequency at 4 weeks and 6 months and fibre intake at 2 years (online supplementary figures $S 2 a$ \& S2b).

Hard stools at 4 weeks (ie, when the diet is milk containing no fibre) and 6 months predicted a lower fibre intake at 2 years (table 1). At this time in the early 1990s, weaning children to solids that contain fibre was recommended at 4 months of age.

There was a strong association between hard stools at 2.5 years (table $2 \mathrm{a}$ and online supplementary figure S3), as well as constipation at $4-10$ years (table $2 \mathrm{~b}$ ) with fibre intake at 2 years.

\section{Dataset 3: twin data}

US, Japanese and UK data all showed similar trends with monozygotic twins more likely to be concordant for constipation than dizygous twins $(\mathrm{p}<0.01)$ (individual study data not shown). Overall, 59\% of childhood constipation can be explained by genetic predisposition (table 3 ).

\section{DISCUSSION}

This paper uses three research approaches to examine the statement 'Lack of fibre in the diet causes constipation in children'.

NICE guideline CG99 (including the 2017 update) ${ }^{4}$ found that a limited number-six-good quality trials were avail$a_{b l e}{ }^{8-13}$; however. they provided no support for the use of fibrerich foods and limited evidence for the use of fibre supplements in treating constipation. The European and North American Societies for Paediatric Gastroenterology Hepatology and Nutrition consensuses recommend a normal fibre intake for children and adolescents with constipation. ${ }^{27}$ A 2018 systematic review

Table $2 \mathrm{a} \quad$ Association between fibre intake at age 2 years and hard stool frequency at age 2.5 years

\begin{tabular}{|c|c|c|c|c|c|}
\hline & & Never & Sometimes & Usually & \\
\hline & $\mathrm{N}$ & OR $(95 \% \mathrm{Cl})$ & $\mathrm{OR}(95 \% \mathrm{Cl})$ & OR $(95 \% \mathrm{Cl})$ & Omnibus $p$ \\
\hline Unadjusted & 9452 & $1.00 \mathrm{ref}$ & 0.904 (0.852 to 0.958$)$ & $0.811(0.761$ to 0.865$)$ & $P<0.001$ \\
\hline Adjusted 1 & 7481 & $1.00 \mathrm{ref}$ & 0.834 (0.773 to 0.899$)$ & $0.789(0.726$ to 0.856$)$ & $P<0.001$ \\
\hline Adjusted 2 & 6141 & $1.00 \mathrm{ref}$ & 0.854 (0.783 to 0.931$)$ & $0.817(0.744$ to 0.897$)$ & $P<0.001$ \\
\hline
\end{tabular}

Adjusted 1: adjusted for the following list of variables: sex, measures of SES (social class, early parenthood and maternal education), household income, housing tenure and material hardship.

Adjusted 2: further adjusted for breastfeeding duration in first 6 months and timing of introduction of both milk and solids.

Table $2 \mathrm{~b}$ Association between fibre intake at age 2 years and longitudinal patterns of childhood constipation (4-10 years)

\begin{tabular}{|c|c|c|c|c|c|c|}
\hline & & Low risk of constipation & Late childhood occurrence & Early childhood occurrence & Persistent constipation & \\
\hline & $\mathrm{N}$ & OR $(95 \% \mathrm{Cl})$ & OR $(95 \% \mathrm{Cl})$ & OR $(95 \% \mathrm{Cl})$ & OR $(95 \% \mathrm{Cl})$ & Omnibus $p$ \\
\hline Unadjusted & 8401 & $1.00 \mathrm{ref}$ & 1.147 (1.008 to 1.305$)$ & 1.040 (0.917 to 1.179$)$ & 0.812 (0.724 to 0.912$)$ & $P<0.001$ \\
\hline Adjusted* & 6784 & $1.00 \mathrm{ref}$ & 1.071 (0.916 to 1.253$)$ & 0.971 (0.832 to 1.134$)$ & 0.748 (0.643 to 0.869$)$ & $P=0.002$ \\
\hline
\end{tabular}

All estimates represent the change in multinomial odds for a 1 SD change in the continuous measure of fibre intake.

*Adjusted model has included the following list of variables: sex, sociodemographic variables, gestation age, birth weight and developmental level of a child at 18 months. 
Table 3 Concordance of constipation comparing identical monozygotic (MZ) and non-identical dizygous (DZ) twins (all studies pooled)

\begin{tabular}{|c|c|c|c|c|c|c|c|c|}
\hline & Twin status & $\begin{array}{l}\mathrm{N}(\%) \\
\text { Both fine }\end{array}$ & $\begin{array}{l}\mathrm{N}(\%) \\
\text { One twin } \\
\text { affected }\end{array}$ & $\begin{array}{l}\text { N (\%) Both } \\
\text { twins affected }\end{array}$ & $\begin{array}{l}\text { Fisher's exact } \\
\text { test }\end{array}$ & $\begin{array}{l}\% \text { with } \\
\geq 1 \text { twin } \\
\text { affected }\end{array}$ & $\begin{array}{l}\text { Concordance } \\
\text { rate }\end{array}$ & Heredity \\
\hline \multicolumn{9}{|c|}{$\begin{array}{l}\text { All studies pooled together } \\
\text { Parent-reported constipation }\end{array}$} \\
\hline \multirow[t]{2}{*}{ Age 3-19 years } & Identical MZ ( $n=291)$ & $256(88)$ & $13(4)$ & $22(8)$ & $P<0.01$ & 12 & 0.63 & $59 \%$ \\
\hline & Non-identical DZ $(n=185)$ & $155(84)$ & $27(15)$ & $3(2)$ & & 17 & 0.10 & \\
\hline
\end{tabular}

Concordance=number with both twins affected divided by the number with both affected+number with one affected. Therefore, if twins are always both affected concordance= 1 and if only one twin is ever affected concordance $=0$.

and meta-analysis that included five of the six trials reported by $\mathrm{NICE}^{8-101213}$ and four additional trials ${ }^{28-31}$ concluded 'there is no scientific evidence to corroborate the prescription of fiber supplementation in the diet of constipated children as part of the treatment of this condition'. ${ }^{32}$ If a low-fibre diet caused childhood constipation, then a diet high in fibre or added fibre should effectively treat constipation, rather than having 'no or little effect'. ${ }^{4}$

ALSPAC findings indicate that 'hard stools' the strongest predictor of later constipation, ${ }^{19}$ can both precede weaning (when fibre commences in the diet) and predict later fibre intake. We know that constipation often leads to reduced appetite ${ }^{33}$ when parents describe their children as 'fussy eaters', where dietary intake is low in fibre rich fruit and vegetables. ${ }^{6}$ The clinical observation that diet in amount and variety often improves by effectively treating constipation with laxatives particularly stool softeners fits in with these findings.

Finally, twin data indicate that $59 \%$ of childhood constipation can be explained as a genetic or natural phenomenon rather than being caused by a low intake of fibre. Genetic studies of functional bowel disorders, ${ }^{34}$ which include idiopathic constipation, indicate a similar level of genetic influence.

The purpose of triangulation is to try to eliminate bias by answering a question with more than one methodology so that possible biases will be different. If all (three in this case) methods point in the same direction and possible biases are not thought to act in the same direction, then stronger claims about cause can be made. Clinical trials of fibre intake (NICE guideline) can suffer from bias from poor compliance. However, if increased fibre intake cannot be sustained in well-resourced clinical trials, it is unlikely to be better tolerated in clinical practice. Bias in observational studies (ALSPAC) is often related to residual sociodemographic confounding. Multiple sociodemographic variables were controlled for (online supplementary table S3). It is interesting to note that fibre intake was strongly related to sociodemographic status but constipation was not. ${ }^{19}$ Finally, twin studies can suffer from poor definition of zygosity that may dilute findings of genetic influence. However, all three studies of twins have findings in the same direction. Although numbers remain small they show statistical significance and agree with other studies documenting the hereditary nature of functional bowel disorders. $^{34}$

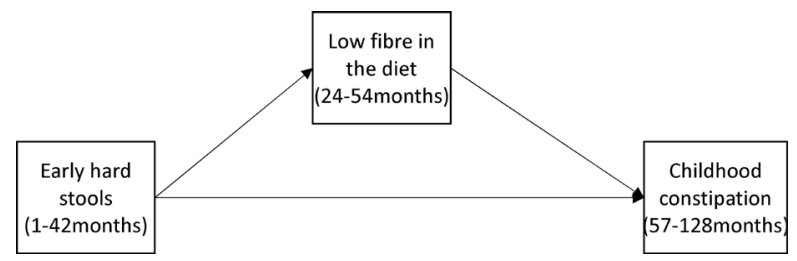

Figure 1 Timeline of hard stools leading to a lower fibre diet and later constipation.
Together these three approaches provide strong evidence to reconsider the conventional view, that a low fibre diet is the cause of constipation in children.

\section{Strengths and weaknesses in relation to other studies, discussing important differences in results}

The strength of this study is the use of triangulation as a method to test causation. ${ }^{7}$ NICE CG99 and a recent systematic review fail to show that fibre is an effective treatment. ALSPAC indicates that early signs of constipation-hard stools at 4 weekscan precede fibre at weaning - 4 months in the 1990s-and predict subsequent low fibre intake. This puts in doubt lack of fibre as the cause of constipation. Twin studies show that most constipation in childhood can be explained by inheritance and not therefore primarily caused by lack of fibre.

It must be noted that a low level of fibre age 2 years (ALSPAC) was strongly associated with later constipation. These cohort data are in keeping with many cross-sectional studies. ${ }^{35} 36$ However, the strength of ALSPAC relates to the longitudinal nature of the cohort from birth. Most previous studies have examined constipation after fibre introduction at weaning (age 4-6 months). ALSPAC measured hard stools at 4 weeks before fibre. If signs of later constipation (hard stools) precede fibre, then for those children low fibre is not the primary cause. Figure 1 illustrates the possible timeline of early hard stools, low fibre intake and later constipation.

A similar mechanism was put forward in a recent cohort study. $^{6}$

Limited data have been reported regarding twins and concordance for constipation. One study has been well documented. ${ }^{22}$ Even after pooling of data, the numbers we report are fairly small; however, there is a significant difference in concordance between monozygotic and dizygous twin pairs.

\section{Meaning of the study: possible explanations and implications for clinicians and policymakers}

Constipation is common (10\% of children) and often chronic, severely debilitating and may have long-term devastating physical and psychological sequelae. This paper indicates that the observed association between low fibre and constipation is unlikely to be directly causal. If further research concludes that hard stools and constipation in childhood are largely inherited, this infers a different cause to the current societal focus on diet. This conclusion is supported by CG99 that found that a highfibre diet did not effectively treat childhood constipation. The shift in focus away from fibre is backed up by ALSPAC, which showed that hard stools can precede weaning (to fibre) and predict a later low-fibre intake, supported by another cohort from the Netherlands. ${ }^{6}$ These observational data may explain why increasing fibre is not very effective. ${ }^{4} 37$ Future research should move away from increasing fibre to genetic studies starting with twins who present with childhood constipation. If 
hard stools and constipation are caused by genetic predisposition and early hard stools predict a low-fibre intake, treatment should focus on softening stools over an extended period, particularly early in life when relief of hard stools may improve long-term fibre intake. ${ }^{6}$ NICE guideline CG99 ${ }^{4}$ states: 'Do not use dietary interventions alone as first-line treatment for idiopathic constipation'. This study begins to clarify the aetiological reasons for that evidence-based statement and will support more clinicians to adhere to this important guidance.

Acknowledgements We are extremely grateful to all the families who took part in this study, the midwives for their help in recruiting them and the whole Avon Longitudinal Study of Parents and Children (ALSPAC) team, which includes interviewers, computer and laboratory technicians, clerical workers, research scientists, volunteers, managers, receptionists and nurses. The UK Medical Research Council and the Wellcome Trust (Grant ref: 102215/2/13/2) and the University of Bristol provide core support for ALSPAC. This publication is the work of the authors who will serve as guarantors for the contents of this paper. We would like to acknowledge the use of data taken directly from the paper: Bakwin $\mathrm{H}$, Davidson M. Constipation in twins. Amer J Dis Child 1971;121:179-81. We would like to thank College of Medical, Veterinary \& Life Sciences Glasgow University for funding our request for raw data from the UK Twins Study. We would like to thank Mr Stephen Mcleod National Health Service Greater Glasgow and Clyde for providing the funding for the analysis of the ALSPAC dataset and the UK twin study dataset.

Contributors DT conceived the study, researched the study areas, wrote the paper and help to design the analysis. MG analysed the ALSPAC dataset. CJ helped conceive the study and edited multiple drafts of the paper. JH helped conceive the study, supervised MG, designed the analysis including triangulation, analysed the twin study data and commented on multiple drafts of the paper.

Funding This research received grant funding from NHS Greater Glasgow and Clyde Health Board.

\section{Competing interests None declared.}

Patient consent for publication Participants gave informed consent.

Ethics approval Ethical approval was obtained from the ALSPAC Ethics and Law committee and local research ethics committees (http://www.bristol.ac.uk/alspac/ researchers/research-ethics/Research Ethics Committee approval references.pdf./). Participants gave informed consent.

Provenance and peer review Not commissioned; externally peer reviewed.

Data availability statement All data relevant to the study are included in the article or uploaded as supplementary information. ALSPAC data can be applied for from the The ALSPAC Study Team (alspac-exec@bristol.ac.uk)

Open access This is an open access article distributed in accordance with the Creative Commons Attribution Non Commercial (CC BY-NC 4.0) license, which permits others to distribute, remix, adapt, build upon this work non-commercially, and license their derivative works on different terms, provided the original work is properly cited, appropriate credit is given, any changes made indicated, and the use is non-commercial. See: http://creativecommons.org/licenses/by-nc/4.0/.

\section{REFERENCES}

1 Tabbers MM, Boluyt N, Berger MY, et al. Constipation in children. BMJ Clin Evid 2010;2010:0303.

2 Collis D, Kennedy-Behr A, Kearney L. The impact of bowel and bladder problems on children's quality of life and their parents: a scoping review. Child Care Health Dev 2019:45:1-14.

3 Müller-Lissner SA, Kamm MA, Scarpignato C, et al. Myths and misconceptions about chronic constipation. Am J Gastroenterol 2005;100:232-42.

4 National Institute for Health and Care Excellence (NICE). Constipation in children and young people: diagnosis and management (CG99) evidence-based recommendations on diagnosing and managing constipation in children and young people. Available: https://www.nice.org.uk/search?q=CG99

5 Silver E. Family therapy and soiling. J Fam Ther 1996;18:415-32.

6 Tharner A, Jansen PW, Kiefte-de Jong JC, et al. Bidirectional associations between fussy eating and functional constipation in preschool children. J Pediatr 2015;166:91-6.

7 Lawlor DA, Tilling K, Davey Smith G. Triangulation in aetiological epidemiology. Int J Epidemiol 2016;45:1866-86.

8 Kokke FTM, Scholtens PAMJ, Alles MS, et al. A dietary fiber mixture versus lactulose in the treatment of childhood constipation: a double-blind randomized controlled trial. J Pediatr Gastroenterol Nutr 2008:47:592-7.
9 Loening-Baucke V, Miele E, Staiano A. Fiber (glucomannan) is beneficial in the treatment of childhood constipation. Pediatrics 2004;113:e259-64.

10 Castillejo G, Bulló M, Anguera A, et al. A controlled, randomized, double-blind trial to evaluate the effect of a supplement of cocoa husk that is rich in dietary fiber on colonic transit in constipated pediatric patients. Pediatrics 2006;118:e641-8.

11 Horvath A, Dziechciarz P, Szajewska H. Glucomannan for abdominal pain-related functional gastrointestinal disorders in children: a randomized trial. World J Gastroenterol 2013:19:3062-8.

12 Quitadamo P, Coccorullo P, Giannetti E, et al. A randomized, prospective, comparison study of a mixture of Acacia fiber, psyllium fiber, and fructose vs polyethylene glycol 3350 with electrolytes for the treatment of chronic functional constipation in childhood. J Pediatr 2012;161:710-5.

13 Weber TK, Toporovski MS, Tahan S, et al. Dietary fiber mixture in pediatric patients with controlled chronic constipation. J Pediatr Gastroenterol Nutr 2014;58:297-302.

14 Boyd A, Golding J, Macleod J, et al. Cohort Profile: the 'children of the 90s'--the index offspring of the Avon Longitudinal Study of Parents and Children. Int J Epidemiol 2013;42:111-27.

15 Emmett P. Dietary assessment in the Avon longitudinal study of parents and children. Eur J Clin Nutr 2009:63:S38-44.

16 Emmett PM, Jones LR, Northstone K. Dietary patterns in the Avon longitudinal study of parents and children. Nutr Rev 2015;73:207-30

17 Northstone K, Emmett P. The associations between feeding difficulties and behaviours and dietary patterns at 2 years of age: the ALSPAC cohort. Matern Child Nutr 2013:9:533-42.

18 Steer CD, Emond AM, Golding J, et al. The variation in stool patterns from 1 to 42 months: a population-based observational study. Arch Dis Child 2009:94:231-3.

19 Heron J, Grzeda M, Tappin D, et al. Early childhood risk factors for constipation and soiling at school age: an observational cohort study. BMJ Paediatr Open 2018;2:e000230.

20 North K, Emmett P. Multivariate analysis of diet among three-year-old children and associations with socio-demographic characteristics. The Avon longitudinal study of pregnancy and childhood (ALSPAC) study Team. Eur J Clin Nutr 2000;54:73-80.

21 Croffie JM, Fitzgerald JF. Hypomotility Disorders. 1. Idiopathic Constipation. Pathogenesis and Mechanisms of Constipation. In: Walker WA, Sherman PM, Goulet 0 , eds. Pediatric gastrointestinal disease. pathophysiology, diagnosis, management. 4th. Hamilton Ontario Canada: BC Decker Inc, 2004: 1001. ISBN: 1550092405.

22 Bakwin H, Davidson M. Constipation in twins. Am J Dis Child 1971:121:179-81.

23 Abe K, Oda N, Ikenaga K, et al. Twin study on night terrors, fears and some physiological and behavioural characteristics in childhood. Psychiatr Genet 1993;3:39-44

24 Bakwin H. Enuresis in twins. Am J Dis Child 1971:121:222-5.

25 Nussbaum RL, McInnes RR, Willard HF. Chapter 8: Genetics of Common Disorders with Complex Inheritance. In: Thompson \&Thompson Genetics in Medicine. 7th ed. United States. Philadelphia: Saunders/Elsevier, 2007. ISBN: 9781416030805

26 Paediatric Group of the British Dietetic Association. 'Food for the Growing Years' and 'Food for the School Years' Now replaced by Healthy eating for children: Food Fact Sheet. Available: https://www.bda.uk.com/resource/healthy-eating-for-children.htm| [Accessed 27/02/2020].

27 Tabbers MM, DiLorenzo C, Berger MY, et al. Evaluation and treatment of functional constipation in infants and children: evidence-based recommendations from ESPGHAN and NASPGHAN. J Pediatr Gastroenterol Nutr 2014;58:258-274.

28 Üstündağ G, Kuloğlu Z, Kirbaş N, et al. Can partially hydrolyzed guar gum be an alternative to lactulose in treatment of childhood constipation? Turk J Gastroenterol 2010;21:360-4.

29 Chmielewska A, Horvath A, Dziechciarz P, et al. Glucomannan is not effective for the treatment of functional constipation in children: a double-blind, placebo-controlled, randomized trial. Clin Nutr 2011;30:462-8.

30 Mozaffarpur SA, Naseri M, Esmaeilidooki MR, et al. The effect of Cassia fistula emulsion on pediatric functional constipation in comparison with mineral oil: a randomized, clinical trial. Daru 2012;20:83

31 Nimrouzi M, Sadeghpour O, Imanieh MH, et al. Flixweed vs. polyethylene glycol in the treatment of childhood functional constipation: a randomized clinical trial. Iran $J$ Pediatr 2015;25:e425.

32 Piccoli de Mello P, Eifer DA, Daniel de Mello E. Use of fibers in childhood constipation treatment: systematic review with meta-analysis. J Pediatr 2018;94:460-70.

33 Fysekidis M, Bouchoucha M, Mary F, et al. Change of appetite in patients with functional digestive disorder. association with psychological disorders: a crosssectional study. J Gastroenterol Hepatol 2018:33:195-202.

34 Morris-Yates A, Talley NJ, Boyce PM, et al. Evidence of a genetic contribution to functional bowel disorder. Am J Gastroenterol 1998:93:1311-7.

35 Roma E, Adamidis D, Nikolara R, et al. Diet and chronic constipation in children: the role of fiber. J Pediatr Gastroenterol Nutr 1999;28:169-74.

36 Morais MB, Vítolo MR, Aguirre AN, et al. Measurement of low dietary fiber intake as a risk factor for chronic constipation in children. J Pediatr Gastroenterol Nutr 1999:29:132-5.

37 Tabbers MM, Benninga MA. Constipation in children: fibre and probiotics. BMJ Clin Evid 2015:2015:0303. 